\title{
Strategies for managing the destruction of calcar femorale
}

\author{
Jin Mei ${ }^{*}$, Lili Pang and Zhongchao Jiang
}

\begin{abstract}
Background: The calcar femorale was identified long ago. However, our current understanding of the calcar is insufficient, and its related concepts are sometimes confused. The calcar femoral is an important anatomical structure of the proximal femur, and its function can be overlooked. In trauma, tumors, or other diseases, the calcar femorale can be destroyed or changed pathologically. As a result, the mechanical structure of the proximal femur becomes destroyed, causing pathological fractures. How to address the destruction of the calcar femorale or the damage to the calcar femorale is discussed in this article.

Main text: Destruction of the calcar femorale is accompanied by many conditions, including trauma, tumors, and other diseases. The types of hip fractures caused by trauma include femoral neck fractures and intertrochanteric fractures. Dynamic hip screws, proximal femoral nail anti-rotation, and multiple parallel cannulate pins can be used in different conditions. When metastatic and primary bone tumors involve the calcar femorale, endoprostheses are widely used. Other diseases, such as fibrous dysplasia and aneurysmal bone cyst are treated differently.

Conclusions: The calcar femorale can redistribute stresses and the destruction of the calcar femorale can lead to an increase in posterior medial stress. Many factors need to be considered when deciding whether to reconstruct the calcar femorale. Effective treatment strategies for managing the destruction of calcar femorale will need first establishing the precise mechanism of the destruction of the calcar and then designing therapies towards these mechanisms. Further investigation to the calcar needs to be carried out.
\end{abstract}

Keywords: Calcar femorale, Intertrochanteric fractures, Femoral neck fractures, Tumors

\section{Background}

The calcar femorale is an anatomical structure of the hip, its related concepts are often confused, and its clinical significance needs to be better understood. Wolff proposed the concepts called the "law of bone remodeling" and "the response of the bone", where the anatomy of the bone is considered compatible with the biomechanics it bears $[1,2]$. These concepts were explained further by Frost HM: modeling and remodeling of the bone are completed by osteoblastic drifts and osteoclastic drifts [3]. Thus, the calcar femorale plays an important role in the biomechanics of the proximal femur. The

\footnotetext{
* Correspondence: meijin@stu.cdutcm.edu.cn

Hospital of Chengdu University of Traditional Chinese Medicine, Chengdu 610072, Sichuan Province, China
}

load transmitted from the femoral head to the upper femur does not follow a straight line considering the femoral neck-shaft angle and the anteversion angle. The force of the femoral neck under physiological loads is a combination of compressive stress, tensile stress, and shear force. The calcar femorale is sometimes destroyed in trauma or disease. Our understanding of the impact of the destruction of the calcar femorale is incomplete, and the optimal treatment strategy remains unclear.

\section{Main text}

The calcar femorale and its function

The Discovery of the calcar femorale is a tortuous process [4]. The calcar femorale was first described in 1827. Charles B proposed that cancelli or minute lattice-

(c) The Author(s). 2021 Open Access This article is licensed under a Creative Commons Attribution 4.0 International License, which permits use, sharing, adaptation, distribution and reproduction in any medium or format, as long as you give appropriate credit to the original author(s) and the source, provide a link to the Creative Commons licence, and indicate if changes were made. The images or other third party material in this article are included in the article's Creative Commons licence, unless indicated otherwise in a credit line to the material. If material is not included in the article's Creative Commons licence and your intended use is not permitted by statutory regulation or exceeds the permitted use, you will need to obtain permission directly from the copyright holder. To view a copy of this licence, visit http://creativecommons.org/licenses/by/4.0/ The Creative Commons Public Domain Dedication waiver (http://creativecommons.org/publicdomain/zero/1.0/) applies to the data made available in this article, unless otherwise stated in a credit line to the data. 
work is an element of the interior structure of bone, and is related to the forces acting on the bone. In 1858, Humphry first described the calcar femorale as "cancelli radiating from the posterior wall of the neck". The calcar femorale is complex (Fig. 1), the terms calcar, calcar area and calcar femorale are often used interchangeably. Calcar femorale and The Adams arch are often confused (Fig. 1c). The previous perception that the calcar femorale disappears when people become middle-aged proved to be wrong [5]. And lateral cortical thickness and the bone mass of the calcar femorale increases with weight and decrease with age in both men and women [6]. The density and stiffness of the calcar femorale are only slightly less than those of cortical bone from the midshaft of the femur in middle-aged and elderly individuals [7]. At the two-dimensional level, the calcar femorale can be divided into three types according to its size on CT cross-sectional images: the ridge type, spur type, and septum type (Fig. 2). Le Corroller et al. describe the calcar as existing in three different shapes of different sizes, the mean length being $3 \mathrm{~mm}$, height $9.94 \mathrm{~mm}$ and thickness $2.71 \mathrm{~mm}$ [8]. Hammer A gave a more detailed description: the calcar femorale lies directly under the upper part of the lesser trochanter. Medially it is attached to the lower part of the vertical trabecular column. Superiorly it has an attachment with the horizontal trabeculae column. Laterally it attaches to the protruding buttress [9].
Regarding the function of the calcar femorale, the calcar femorale and the three types of bone trabeculae consist of compression, oblique and tension trabeculae, forming the loading system-truss system. The three types of bone trabeculae increase the rigidity of the passing area by 160 to $400 \%$. Zhang Y found that the compression forces were mainly concentrated on the medial surface of the femur by a finite element analysis [10]. The anterior wall of the femur at the calcar's level is strong and thick but the posterior wall is otherwise. Bigelow even proposed that the calcar femorale is the true posterior wall of the upper femur [11]. Although people have different opinions on aspects of the calcar femorale (Table 1), its functional support and mechanical transmission properties at the proximal femur cannot be ignored. Farkas et al. suggested that the calcar femorale is an internal weight-bearing system of the proximal femur [12]. Li B proposed that the calcar femorale is a supporting structure to the femoral neck and can transfer stress from the trabecular bone of the femoral head and neck to the femoral shaft [13]. The posterointernal parts of the proximal femur bear more strain than do the anterolateral and calcar femorale parts, which play a significant role in redistributing stress along the proximal femur [14]. The stress is redistributed by decreasing the load in the posterointernal aspects and increasing the load in the anterolateral aspects. Therefore, the calcar femorale is a ridge of dense
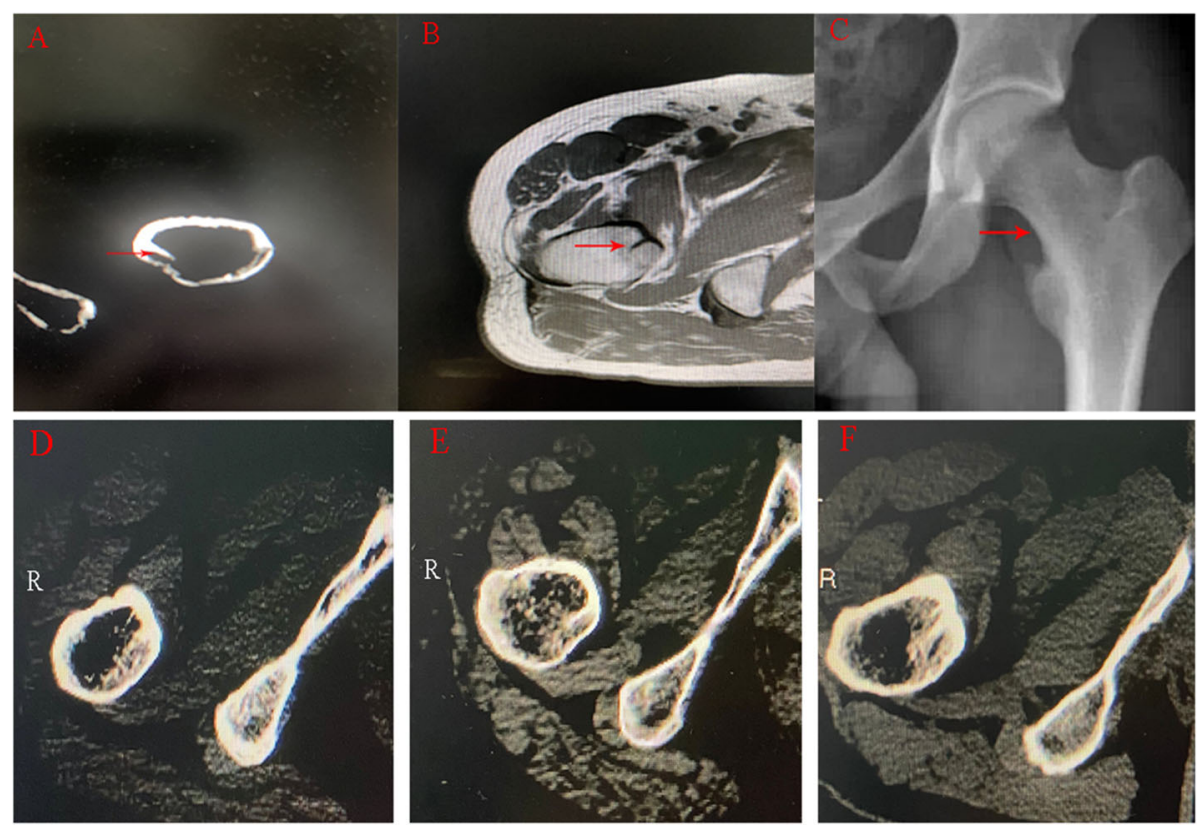

Fig. 1 a The spur type of the calcar femorale can be seen in cross-sectional computed tomography images (red arrow) b The calcar femorale has a low signal in T1 weighted magnetic resonance images (red arrow) c The Adams arch (red arrow) is often confused with the calcar femorale. These three cross-sectional computed tomography images are from different individuals, the calcar femorale is classified into three types according to its length and thickness. $\mathbf{d}$ ridge-type: the calcar femorale is short and thick. e spur-type: the calcar femorale is longer than ridgetype and like a spur. $\mathbf{f}$ septum-type: the calcar femorale is thin and long 


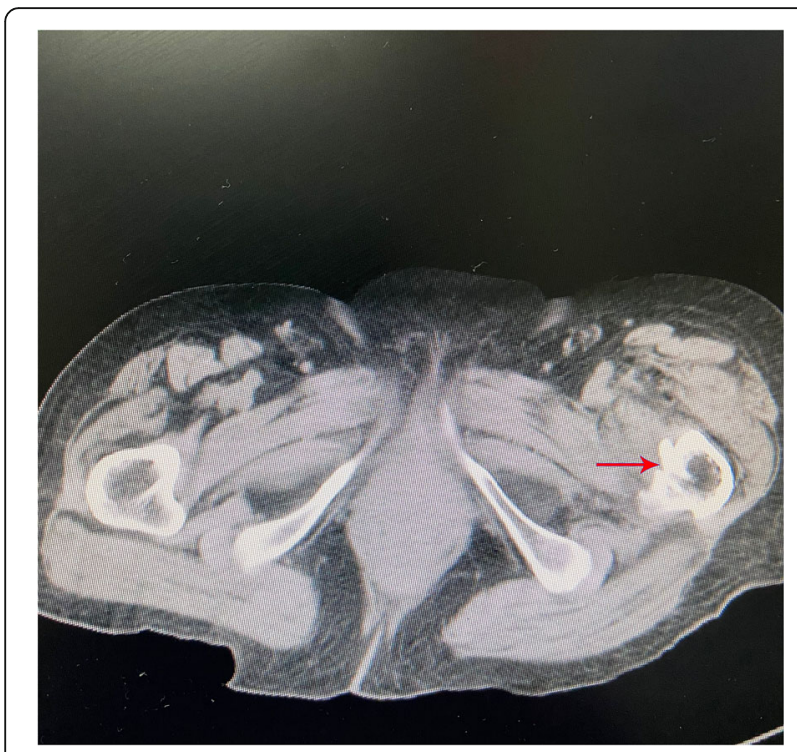

Fig. 2 Destruction of the calcar femorale (red arrow) in crosssectional computed tomography image of the right hip with an intertrochanteric fracture

bone along the posteromedial endosteal surface of the proximal femoral shaft near the lesser trochanter. It is vertical in orientation, and it projects laterally toward the greater trochanter. The calcar femorale provides mechanical support and plays an important role in load distribution within the proximal femur [15].

\section{Fractures}

Hip fracture patients have a high risk of death compared to the general population [16]. For proximal femoral fractures with an intact calcar femorale, it is better to fix the internal fixation device at a position close to the calcar femorale. This method not only strengthens the calcar femorale but also preserves the distribution of compression forces and load transmission of the proximal femur. The destruction of the calcar femorale has a large impact on the mechanical structure of the entire

Table 1 Different viewpoints on the function of the calcar femorale

\begin{tabular}{lll}
\hline Authors & Years & The function of calcar femoral \\
\hline Farkas et al. [12] & 1948 & $\begin{array}{l}\text { An internal weight bearing system } \\
\text { of the femoral neck. }\end{array}$ \\
Li and Aspden [13] & 1998 & $\begin{array}{l}\text { A supporting structure to the } \\
\text { femoral neck and can transfer stress } \\
\text { from the trabecular bone of the } \\
\text { femoral head and neck to the } \\
\text { femoral shaft }\end{array}$ \\
Zhang et al. [14] & 2009 & $\begin{array}{l}\text { Bears compression load and } \\
\text { redistributes stress or load from the } \\
\text { femoral head to the proximal femur }\end{array}$ \\
\hline
\end{tabular}

femur, thereby affecting the optimal procedures. The calcar femorale is a frequently mentioned concept in the treatment of intertrochanteric and femoral neck fractures. We often hear phrases such as "nailing against the calcar femorale", " carefully protect the calcar femorale" and "the calcar is destroyed". specific analysis is described below.

\section{Intertrochanteric fractures}

Intertrochanteric fractures often result in a shattered calcar near the junction between the femoral shaft and the lesser trochanter (Fig. 2). Xiong et al. reported in a morphologic study that $87 \%$ of the lesser trochanter fragment contains the calcar femorale [17]. Naimark A proposed that the stability of intertrochanteric fractures depends on the obliquity of the fracture line and the critical calcar area [18]. Seker A also found a high level of stress at the calcar femorale after proximal femoral nail fixation of trochanteric fractures when assessing the effects of early weight bearing [19].

Evans classification system is commonly used for intertrochanteric fractures. Harris $\mathrm{WH}$ et al. implemented mechanical tests in intertrochanteric fractures with fracture masses of different sizes in the posterior medial region. He found that fixation of the posteromedial fragment, especially the calcar femorale, is important to the structural stability of hips [20]. DHSs (Dynamic Hip Screws) may be a better choice for stable fractures of Evans types I and II. When DHSs have applied in Evans type III fractures, screw bending often occurs because compressive stresses cannot be transmitted through the calcar femorale. The destruction of the calcar femorale affects the crucial weight-bearing area of the proximal femur and leads to the unsuccessful treatment of unstable intertrochanteric fractures [21]. Compared to DHSs, proximal femoral nail anti-rotation (PFNA) is a satisfactory fixation method for unstable intertrochanteric fractures [22]. However, a poor calcar femorale restoration is also one of the risk factors for the failure of unstable intertrochanteric fractures after PFNA [18]. The calcar fractures also increase the risk of revision after cementless total hip arthroplasty [23]. Thakkar CJ found that $94 \%$ of patients who underwent hemiarthroplasty with calcar femorale grafting achieved a satisfactory outcome with few complications [24]. An integral calcar femorale is critical to maintaining the stability of the internal fixators. Therefore, satisfactory calcar reduction can lead to a satisfactory outcome and decrease the risk of complications [25]. However, Zha GC holds different views: for elderly patients with unstable intertrochanteric fractures, bipolar hemiarthroplasty using cementless distal fixation modular prostheses achieves satisfactory mid-term radiographic and clinical outcomes without reconstruction of the calcar femorale [26]. 


\section{Femoral neck fractures}

Femoral neck fractures with the destruction of the calcar femorale are rarely seen in clinical practice and are easily overlooked. The optimal surgical treatment for femoral neck fractures remains controversial. The degree of displacement and comminution of the calcar femorale, varus angulation and size of the femoral head can affect the effects of treatment for femoral neck fractures. DHSs and multiple parallel cannulate screws are the most commonly used internal fixation techniques. Multiple parallel cannulate screws can prevent secondary displacement and reduce the risk of femoral head necrosis. However, how to place the screw at the best position in the limited intramedullary space still needs to be discussed. Placement of the cannulate screws close to the posterior cortex and calcar femorale can decrease the risk of reoperation. From Lindequist's viewpoint, the rationale for placing the fixation device close to the calcar in femoral neck fractures is that the fracture will subside until the cannulated screws abut the intact cortex of the calcar femorale $[27,28]$. In a study of proximal femur morphology, Nakanishi Y also found that the anterior cannulate screw position affected the calcar [29]. Filipov O proposed that biplane double-supported screw fixation (BDSF) with two cannulate screws buttressed on the calcar can provide additional cortical support [30]. In the treatment of high-shear Pauwels III femoral neck fractures with cannulated screws, Tianye L compared four different internal fixations and found that the "F" cannulate screw technique may be a good method. It can eliminate shear and torsional stresses and exert compressive stresses on the fracture end, but more clinical trials are needed to confirm this finding [31]. In a study comparing 3 different cannulate screw configurations for unstable femoral neck fractures, a transverse screw in the calcar was shown to provide a more stable structure [32]. Satisfactory reduction of the calcar femorale can minimize complications and improve functional outcomes [33]. For patients with posteromedial calcar fragments, the proximal end of the DHS is fixed with a cannulated screw also can obtain anti-rotation stability and good support [34].

\section{Intraoperative fractures}

The operation can also lead to the destruction of the calcar femorale. The calcar crack was first described by Mont et as the most common intraoperative fracture [35]. Intraoperative fractures of the calcar femorale are often occurred in cementless total hip arthroplasty (THA) [36]. Its incidence varies from 0.1 to $11 \%$ [37, 38]. Intraoperative fractures with uncemented components often occur in patients with dysplastic femurs and women $[39,40]$. The proximal femoral shape also affects the risk of intraoperative fractures of the calcar femorale. Patients who have smaller and narrower femurs are more susceptible to an intraoperative fracture of the calcar [41]. For deviant-shaped proximal femurs, cementless stems should be installed with care to avoid artificial damage to the calcar femorale. Cerclage wires or cables may be a good method for stabilizing calcar crack [42]. Because it can resist the stresses of axial and rotational on the stem [43].

\section{Tumor}

The proximal femur is a common site for primary bone tumors and influences the mechanical structure of the proximal femur (Fig. 3). Patients are typically diagnosed with a tumor of the proximal femur after they had a pathological fracture [44]. Patients diagnosed with proximal femur tumors have different demographic characteristics, and their oncologic survival rates are different. With an extended survival time, many survivors expect to have an active lifestyle and good quality of life. Therefore, the improvement on function and implant longevity is more important after the proximal femur is resected [45, 46].

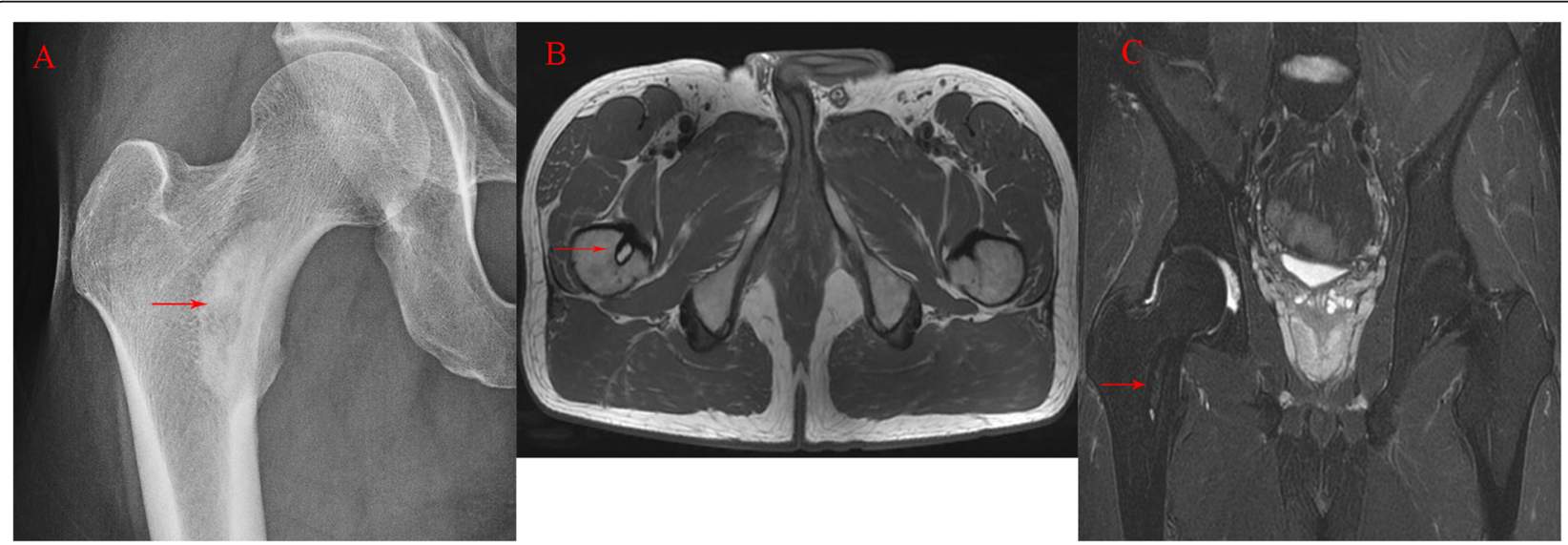

Fig. 3 a An enchondroma is located in the calcar femorale in the coronal-view plain radiography (red arrow) $\mathbf{b} \mathbf{c}$ It is also can be seen in a transverse plane of $\mathrm{T} 1$ weighted magnetic resonance image and the coronal plane of $\mathrm{T} 2$ weighted magnetic resonance image respectively 
However, there aren't standardized guidelines or clinical study results that can guide the choice of appropriate operative procedures. Osteosynthetic fixation and prosthetic replacement are common operative procedures [47, 48], but which procedure is better is still debated. Life expectancy and the performance status before fracture are the main factors affecting the operative procedures [49]. and another important factor, the degree of bone destruction, was discussed in one study [50]. prosthesis applies to the following bone destruction factors: 1 . Involvement of the head, neck, calcar femorale, and intertrochanteric region 2. Transverse destruction $>50 \% 3$.Tumor extension to soft-tissue. Cho HS reviewed 7 patients with tumors involving the proximal femur: conventional total hip prostheses with calcar preservation yielded satisfactory outcomes [51].

\section{Tumor-like lesions}

Fibrous dysplasia is a nonhereditary benign disease in which normal bone tissue is replaced by abnormally hyperplastic immature reticular bone and fibrous tissue. It can be divided into three clinical types: monostotic, polyostotic and McCune-Albright syndrome [52]. When the lesion progresses to the proximal part of the femur, the mechanical forces lead to progressive varus and bowing deformities or pathological fractures in most patients [53]. Guille JT declared that the calcar was not involved in cases with a monostotic lesion in his study group and these patients had less severe deformities. However, for patients who have polyostotic lesions, and the calcar is often involved, medial displacement osteotomy is an effective treatment [54].

Aneurysmal bone cysts (ABCs) are benign single bone tumors characterized by a uniform foam-like translucent area within the tumor. Weber MG founded that one patient had a pathologic fracture when the lesion area occurred at intertrochanteric and calcar femorale [55]. The accepted treatment is curettage and bone grafting when pathologic fractures occur [56]. However, internal fixation is mandatory when the fracture reaches the critical weight-bearing area. Curettage with bone grafting and cephalomedullary nail fixation may be an effective treatment for patients with a pathological fracture secondary to $\mathrm{ABC}$.

\section{Discussion}

The calcar femorale plays a core role in dealing with the complex forces that occur at the junction of the femoral shaft and neck. It is an important part of the internal weight-bearing structure of the upper femur. It also can redistribute the stresses of the proximal femur, reduce the posterior and medial cortical loads and increase the anterior and lateral cortical loads, and make the process of transmitting stress from the femoral head to the femoral shaft more reasonable. Reduction of the calcar femorale can effectively improve the mechanical transmission of the proximal femur. Strategies for managing the destruction of the calcar femorale are shown in the flow chart below (Fig. 4). In hip fractures, the type of fracture should be considered first, and different procedures can be selected according to whether the calcar is involved. As for tumors, life expectancy is the main factor in deciding whether to operate and the degree of bone destruction should also be evaluated. Different procedures can be selected in other diseases involving the calcar.

Clinical studies have revealed that the incidence of intertrochanteric fractures gradually increases with age $[57,58]$. Some scholars believe that this finding is related to the calcar femorale. The density and stiffness of the calcar femorale are only slightly less than those of cortical bone from the mid-shaft of the femur in middleaged and elderly individuals. The femoral trochanter is the place with the lowest bone mineral density in the hip and the most sensitive part of bone loss. Low bone mass and fragile bone structures are the main cause of hip fractures in this region [59]. Some researchers believe that for every increase in bone density by one standard deviation, the risk of fracture increases by 2 to 3 times [60]. So bone mass can also be used as a predictor for hip fractures [61]. There are no significant differences in the density or rigidity of the calcar femorale between osteoporosis patients and normal people. Therefore, it is osteoporosis rather than changes in the calcar femorale that increases the risk of intertrochanteric fractures.

For stable femoral neck fractures, multiple cannulate screws are commonly used for internal fixation [62]. However, putting the screw in the best position is still needs discussion in the limited intramedullary space. Lindequist put forward that the cannulate screws close to the calcar can accelerate the healing of the fracture, and Filipov $\mathrm{O}$ also proposed that two cannulate screws buttressed on the calcar can provide additional cortical support. However, for unstable femoral neck fractures (Pauwels III), a study proposed that a transverse screw in the calcar can provide a more stable structure after comparing 3 different cannulate screw configurations. Tianye L compared four different internal fixations and found that the " $F$ " cannulate screw technique may be a good method. When using DHSs to treat unstable intertrochanteric fractures, putting the screw posterior and inferior to the femoral head may help support the posteromedial cortex and calcar femorale and decrease the risk of cut-out [63]. It is recommended that the proximal end of the DHS is fixed with a cannulated screw. Therefore, the relationship between internal fixation and the calcar femorale is strong. 


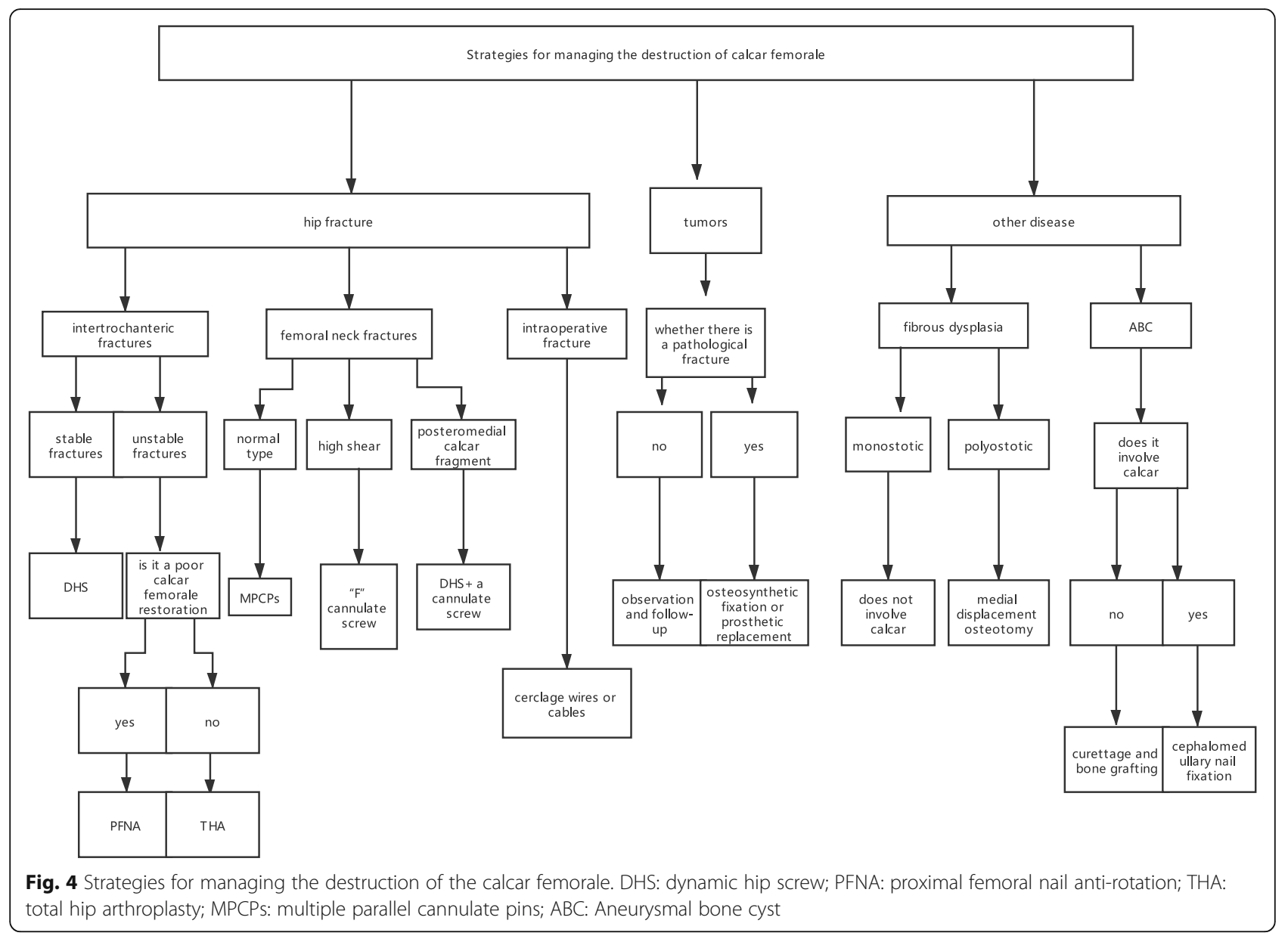

The primary complication of THA remains aseptic loosening [64]. Periprosthetic bone loss and bone resorption are crucial factors that lead to aseptic loosening [65]. The calcar femorale prevents aseptic loosening and subsidence. Some scholars believe that the femoral neck should be kept $1.0 \sim 1.5 \mathrm{~cm}$ above the trochanter, which can prevent the destruction of the calcar femorale, thereby preventing the subsidence of prosthesis, and reducing the incidence of hip varus and length discrepancies between the lower limbs. Many scholars have found that preserving the calcar femorale or rebuilding the calcar during THA can establish a more stable mechanical structure. However, due to the periprosthetic bone loss caused by the stress shielding effect, the medial calcar is the most affected region. Femoral stem design can influence the degree of stress shielding. Advancements in stem material, geometry and design are crucial for restoring a physiologic load transfer through the calcar femorale. Calcar-guided short stems can better adapt the anatomical curvature of the calcar femorale in modern THA than can conventional straight-stem designs. However, the long-term clinical effects need to be studied. In some cases of femoral neck shortening, short stems should also be used, and the calcar femoral should not be removed heavily so that the tension of the gluteus medius muscle can be maintained and subsidence can be prevented. Contacting the collar of a femoral prosthesis with the calcar femorale can increase the vertical stress within the region of the calcar femorale. Calcar collars can improve stability by exerting compressive loads on the calcar and are often used on cementless stems to prevent the subsidence of prostheses [66]. However, some scholars hold different views. Wroblewski $\mathrm{BM}$ proposed that clearing the calcar can provide an adequate cement mantle and decrease the risk of revisions due to aseptic loosening [67]. Zhang GC used bipolar hemiarthroplasty to treat intertrochanteric fractures without reconstruction of the calcar femorale and achieved satisfactory clinical and radiological outcomes. However, preventing subsidence of the stem and maintaining the stability of the implant is a challenge without the calcar femorale.

The calcar femorale has also been used as an important predictive parameter. A cut-out is a common complication after DHSs in intertrochanteric fractures [68]. A tip-apex distance (TAD) less than $25 \mathrm{~mm}$ is recommended to 
decrease the risk of screw cut-out [69]. Later, a new concept of calcar-referenced tip-apex distance (CalTAD) was proposed [70] and is known as a significant cut-out predictor [71]. However, which predictor is better has been debated. CalTAD can also be utilized for helical blade placement. In patients with developmental dysplasia of the hip, the preoperative calcar femorale angles at the low femoral neck can be effective parameters to predict postoperative stem anteversion [72].

There is no unified conclusion about the optimal method of calcar femorale reconstruction. Accordingly, there are varied reconstruction materials, including bone cement, metal mesh, steel plates, steel wire binding and vascularized femoral flaps. Currently, the most commonly used methods include bone cement reconstruction and femoral calcar fracture reduction. A study involving threedimensional finite element analysis showed that the distribution of stresses was more uniform and that the biomechanics were more stable with bone cement reconstruction. But which treatment method is better needs to be studied extensively.

\section{Conclusions}

The calcar femorale can redistribute stresses and the destruction of the calcar femorale can lead to an increase in posterior medial stress. Many factors need to be considered when deciding whether to reconstruct the calcar femorale. Effective treatment strategies for managing the destruction of calcar femorale will need first establishing the precise mechanism of the destruction of the calcar and then designing therapies towards these mechanisms. Further investigation to the calcar needs to be carried out.

\section{Abbreviations \\ DHSs: dynamic hip screws; PFNA: proximal femoral nail anti-rotation; BDSF: biplane double-supported screw fixation; THA: total hip arthroplasty; ABCs: Aneurysmal bone cysts; TAD: tip-apex distance; CalTAD: calcar- referenced tip-apex distance}

\section{Acknowledgements}

Not applicable.

\section{Authors' contributions}

JM collected relevant articles and was a major contributor in writing the manuscript. LLP was responsible for the design of figures and tables. ZCJ provided advice and guidance. All authors read and approved the final manuscript.

\section{Funding}

Not applicable.

\section{Availability of data and materials}

Data sharing is not applicable to this article as no datasets were generated or analysed during the current study.

\section{Declarations}

Ethics approval and consent to participate

All pictures are obtained from the Hospital of Chengdu University of Traditional Chinese Medicine. The picture does not contain personal information. Written informed consent was obtained from the patients.

\section{Consent for publication}

Not applicable.

\section{Competing interests}

The authors declare that they have no competing interests.

Received: 26 September 2020 Accepted: 5 May 2021

Published online: 19 May 2021

\section{References}

1. Wolff J. The law of bone remodelling. In: Maquet P, Furlong $R$, editors. The law of bone Remodelling. Berlin: Springer-Verlag; 1986. p. 1-83.

2. Frost HM. Wolff's law and bone's structural adaptations to mechanical usage: an overview for clinicians. Angle Orthod. 1994;64(3):175-88. https:// doi.org/10.1043/0003-3219(1994)064<0175:WLABSA>2.0.CO;2.

3. Frost HM. From Wolf's law to the Utah paradigm: insights about bone physiology and its clinical applications. Anat Rec. 2001;262(4):398-419. https://doi.org/10.1002/ar.1049.

4. Newell RL. The calcar femorale: a tale of historical neglect. Clin Anat. 1997; 10(1):27-33. https://doi.org/10.1002/(SICI)1098-2353(1997)10:1<27::AID-CA 5>3.0. $\mathrm{CO} ; 2-\mathrm{Q}$

5. Griffin JB. The calcar femorale redefined. Clin Orthop Relat Res. 1982;164: 211-4.

6. Peacock M, Liu G, Carey M, Ambrosius W, Turner CH, Hui S, et al. Bone mass and structure at the hip in men and women over the age of 60 years. Osteoporos Int. 1998;8(3):231-9. https://doi.org/10.1007/s001980050059.

7. Cech O, Kostál R, Váchal J. Unstable pertrochanteric fractures, biomechanic, classification and therapy. Acta Chir Orthop Traumatol Cechoslov. 2000; 67(1):17-27.

8. Le Corroller T, Dediu M, Pauly V, Pirro N, Chabrand P, Champsaur P. The femoral calcar: a computed tomography anatomical study. Clin Anat. 2011; 24(7):886-92. https://doi.org/10.1002/ca.21177.

9. Hammer A. The structure of the femoral neck: a physical dissection with emphasis on the internal trabecular system. Ann Anat. 2010;192(3):168-77. https://doi.org/10.1016/j.aanat.2010.02.007.

10. Zhang Y, Zhong W, Zhu H, Chen Y, Xu L, Zhu J. Establishing the 3-D finite element solid model of femurs in partial by volume rendering. Int I Surg. 2013:11(9):930-4. https://doi.org/10.1016/j.ijsu.2013.06.843.

11. Bigelow $\mathrm{HJ}$. The true neck of the femur: its structure and pathology. Boston Med Surg J. 1875:92(1):1-5. https://doi.org/10.1056/NEJM187501070920101.

12. Farkas RA, Wilson MJ, Hayner C. An anatomical study of the mechanics, pathology, and healing of fracture of the femoral neck. J Bone Joint Surg Am. 1948;30A(1):53-9.

13. Li B, Aspden RM. A comparison of the stiffness, densityand composition of bone from the calcar femorale and thefemoral cortex. J Mater Sci Mater Med. 1998;9(11):661-6. https://doi.org/10.1023/A:1008987626212.

14. Qi Z, Wei $C$, Huai-jun $L$, et al. The role of the calcar femorale in stress distribution in the proximal femur. Orthop Surg. 2009;1:311-6.

15. Hammer A. The calcar femorale: A new perspective. J Orthop Surg (Hong Kong). 2019;27(2):2309499019848778.

16. Panula J, Pihlajamäki $H$, Mattila VM, Jaatinen $P$, Vahlberg $T$, Aarnio $P$, et al. Mortality and cause of death in hip fracture patients aged 65 or older: a population-based study. BMC Musculoskelet Disord. 2011;12(1):105. https:// doi.org/10.1186/1471-2474-12-105.

17. Xiong WF, Zhang YQ, Chang SM, Hu SJ, du SC. Lesser trochanteric fragments in unstable pertrochanteric hip fractures: a morphological study using threedimensional computed tomography (3-D CT) reconstruction. Med Sci Monitor. 2019;25:2049-57. https://doi.org/10.12659/MSM.913593.

18. Naimark A, Kossoff J, Schepsis A. Intertrochanteric fractures: current concepts of an old subject. AJR Am J Roentgenol. 1979;133(5):889-94. https://doi.org/10.2214/ajr.133.5.889.

19. Kaya S, Seker A, Altın Ö, Altuntaș YE, Kaptanoğlu L, Kement M, et al. Evaluation of current therapeutic approach to obstructive and perforated 
colorectal cancers. Ulus Travma Acil Cerrahi Derg. 2019;25(6):589-96. https:// doi.org/10.14744/tjtes.2019.03828.

20. Oh I, Harris WH. Proximal strain distribution in the loaded femur. An in vitro comparison of the distributions in the intact femur and after insertion of different hip-replacement femoral components. J Bone Joint Surg Am. 1978; 60(1):75-85

21. Gurtler RA, Jacobs RR, Jacobs CR. Biomechanical evaluation of the Ender's pins, the Harris nail, and the dynamic hip screw for the unstable intertrochanteric fracture. Clin Orthop Relat Res. 1986;206:109-12.

22. Zhang W, Antony Xavier RP, Decruz J, Chen YD, Park DH. Risk factors for mechanical failure of intertrochanteric fractures after fixation with proximal femoral nail antirotation (PFNA II): a study in a southeast Asian population. Arch Orthop Trauma Surg. 2021;141(4):569-75.

23. Miettinen SS, Mäkinen TJ, Kostensalo I, Mäkelä K, Huhtala H, Kettunen JS, et al. Risk factors for intraoperative calcar fracture in cementless total hip arthroplasty. Acta Orthop. 2016;87(2):113-9. https://doi.org/10.3109/17453 674.2015.1112712.

24. Thakkar CJ, Thakkar S, Kathalgere RT, Kumar MN. Calcar femorale grafting in the hemiarthroplasty of the hip for unstable inter trochanteric fractures. Indian J Orthop. 2015;49(6):602-9. https://doi.org/10.4103/0019-5413.168762.

25. Parry JA, Sapp T, Langford JR, Koval KJ, Haidukewych GJ. Variables associated with lag screw sliding after single-screw Cephalomedullary nail fixation of intertrochanteric fractures. J Orthop Trauma. 2020;34(7):356-8. https://doi.org/10.1097/BOT.0000000000001730.

26. Zha GC, Liu J, Wang Y, Feng S, Chen XY, Guo KJ, et al. Cementless distal fixation modular stem without reconstruction of femoral calcar for unstable intertrochanteric fracture in patients aged 75 years or more. Orthop Traumatol Surg Res. 2019;105(1):35-9. https://doi.org/10.1 016/j.otsr.2018.11.015.

27. Kauffman JI, Simon JA, Kummer FJ, Pearlman CJ, Zuckerman JD, Koval KJ. Internal fixation of femoral neck fractures with posterior comminution: a biomechanical study. J Orthop Trauma. 1999;13(3):155-9. https://doi.org/1 0.1097/00005131-199903000-00001.

28. Lindequist S, Wredmark T, Eriksson SA, Samnegard E. Screw positions in femoral neck fractures. Comparison of two different screw positions in cadavers. Acta Orthop Scand. 1993;64(1):67-70. https://doi.org/10.3109/174 53679308994532.

29. Nakanishi Y, Hiranaka T, Shirahama M, Uesugi M, Okimura K, Tsubosaka M, et al. Ideal screw positions for multiple screw fixation in femoral neck fractures - study of proximal femur morphology in a Japanese population. J Orthop Sci. 2018;23(3):521-4. https://doi.org/10.1016/j.jos.2018.01.012.

30. Filipov O, Stoffel K, Gueorguiev B, Sommer C. Femoral neck fracture osteosynthesis by the biplane double-supported screw fixation method (BDSF) reduces the risk of fixation failure: clinical outcomes in 207 patients. Arch Orthop Trauma Surg. 2017;137(6):779-88. https://doi.org/10.1007/s004 02-017-2689-8

31. Tianye L, Peng Y, Jingli X, QiuShi W, GuangQuan Z, Wei H, et al. Finite element analysis of different internal fixation methods for the treatment of Pauwels type III femoral neck fracture. Biomed Pharmacother. 2019;112: 108658. https://doi.org/10.1016/j.biopha.2019.108658.

32. Gümüștaş SA, Tosun HB, Ağır I, Orak MM, Onay T, Okçu G. Influence of number and orientation of screws on stability in the internal fixation of unstable femoral neck fractures. Acta Orthop Traumatol Turc. 2014:48(6): 673-8. https://doi.org/10.3944/AOTT.2014.14.0088.

33. Boraiah S, Paul O, Gardner MJ, Parker RJ, Barker JU, Helfet D, et al. Outcomes of length-stable fixation of femoral neck fractures. Arch Orthop Trauma Surg. 2010;130(12):1523-31. https://doi.org/10.1007/s00402-010-1103-6.

34. Bonnaire $F$, Kuner EH, Lorz W. Femoral neck fractures in adults: joint sparing operations. II. The significance of surgical timing and implant for development of aseptic femur head necrosis. Unfallchirurg. 1995: 98(5):259-64.

35. Mont MA, Maar DC, Krackow KA, Hungerford DS. Hoop-stress fractures of theproximal femur during hip arthroplasty. Management and results in 19 cases. J Bone Joint Surg Br. 1992;74:257e60.

36. Schramm M, Keck F, Hohmann D, Pitto RP. Total hip arthroplasty using an uncemented femoral component with taper design: outcome at 10-year follow-up. Arch Orthop Trauma Surg. 2000;120(7-8):407-12. https://doi.org/1 0.1007/PL00013771.

37. Jewett BA, Collis DK. High complication rate with anterior total hip arthroplasties on a fracture table. Clin Orthop Relat Res. 2011;469(2):503-7. https://doi.org/10.1007/s1 1999-010-1568-1.
38. Fernandez-Fernandez R, García-Elias E, Gil-Garay E. Peroperative fractures in uncemented total hip arthroplasty: results with a single design of stem implant. Int Orthop. 2008;32(3):307-13. https://doi.org/10.1007/s002 64-006-0318-1.

39. Berend ME, Smith A, Meding JB, Ritter MA, Lynch T, Davis K. Long-term outcome and risk factors of proximal femoral fracture in uncemented and cemented total hip arthroplasty in 2551 hips. J Arthroplast. 2006;21(Suppl 2): 53-9. https://doi.org/10.1016/j.arth.2006.05.014.

40. Berend KR, Lombardi AV Jr, Mallory TH, Chonko DJ, Dodds KL, Adams JB. Cerclage wires or cables for the management of intraoperative fracture associated with a cementless, tapered femoral prosthesis: results at 2 to 16 years. J Arthroplast. 2004;19(Suppl 2):17-21. https://doi.org/10.1016/j.arth.2 004.06.008.

41. Bonnin M P, Neto C C, Aitsiselmi T et al. Increased incidence of femoral fractures in small femurs and women undergoing uncemented total hip arthroplasty - why?. Bone Joint J, 2015, null: 741-8.

42. Park CW, Lim SJ, Ye DH, Park YS. Outcomes of Cerclage cabling for intraoperative Calcar cracks in Cementless Total hip Arthroplasty using broach-only. Tapered Wedge Stems J Arthroplasty. 2020;35(10):3002-9. https://doi.org/10.1016/j.arth.2020.05.041.

43. Waligora ACT, Owen JR, Wayne JS, Hess SR, Golladay GJ, Jiranek WA. The effectof prophylactic cerclage wires in primary total hip arthroplasty: a biome-chanical study. J Arthroplast. 2017;32:2023e7.

44. Hage WD, Aboulafia AJ, Aboulafia DM. Incidence, location and diagnostic evaluation of metastatic bone disease. Orthop Clin North Am. 2000;31(4): 515-28. https://doi.org/10.1016/S0030-5898(05)70171-1.

45. Nooh A, Goulding K, Isler MH, Mottard S, Arteau A, Dion N, et al. Early improvement in pain and functional outcome but not quality of life after surgery for metastatic long bone disease. Clin Orthop Relat Res. 2018;476(3): 535-45. https://doi.org/10.1007/s11999.0000000000000065.

46. Capanna R, Scoccianti G, Frenos F, Vilardi A, Beltrami G, Campanacci DA. What was the survival of megaprostheses in lower limb reconstructions after tumor resections? Clin Orthop Relat Res. 2015;473(3):820-30. https:// doi.org/10.1007/s11999-014-3736-1.

47. Favorito PJ, McGrath BE. Impending or completed pathologic femur fractures treated with intramedullary hip screws. Orthopedics. 2001;24(4): $359 e 63$.

48. Janssen SJ, Langerhuizen DW, Schwab JH, Bramer JA. Outcome after reconstruction of proximal femoral tumors: a systematic review. J Surg Oncol. 2019:119(1):120-9. https://doi.org/10.1002/jso.25297.

49. Katagiri H, Okada R, Takagi T, Takahashi M, Murata H, Harada H, et al. New prognostic factors and scoring system for patients with skeletal metastasis. Cancer Med. 2014;3(5):1359e67.

50. Araki N, Chuman H, Matsunobu T, Tanaka K, Katagiri H, Kunisada T, et al. Factors associated with the decision of operative procedure for proximal femoral bone metastasis: Questionnaire survey to institutions participating the Bone and Soft Tissue Tumor Study Group of the Japan Clinical Oncology Group. J Orthop Sci. 2017;22(5):938-45.

51. Cho HS, Lee YK, Ha YC, Koo KH. Trochanter/calcar preserving reconstruction in tumors involving the femoral head and neck. World J Orthop. 2016;7(7): 442-7. https://doi.org/10.5312/wjo.v7.i7.442.

52. Kaplan FS, Fallon MD, Boden SD, Schmidt R, Senior M, Haddad JG. Estrogen receptors in bone in a patient with polyostotic fibrous dysplasia (McCuneAlbright syndrome). N Engl J Med. 1988;319(7):421-5.

53. De Palma AE, Dodd PM Jr. Reconstructive surgery in fibrous dysplasia of bone. Clin Orthop. 1961;19:132-47.

54. Whiteside LA, Amador D, Russell K. The effects of the collar on total hip femoral component subsidence. Clin Orthop Relat Res. 1988;231: 120-6.

55. Weber MG, Fan J, Jenkins R. An uncommon presentation of an uncommon bone tumor: a case study of a pathologic fracture of an intertrochanteric aneurysmal bone cyst. Cureus. 2019;11(12):6461.

56. Rapp TB, Ward JP, Alaia MJ. Aneurysmal bone cyst. J Am Acad Orthop Surg. 2012;11(4):233-41. https://doi.org/10.5435/JAAOS-20-04-233.

57. Looker AC, Wahner HW, Dunn WL, Calvo MS, Harris TB, Heyse SP, et al. Updated data on proximal femur bone mineral levels of US adults. Osteoporos Int. 1998;8(5):468-89. https://doi.org/10.1007/s001980050093.

58. Lotzien S, Rausch V, Schildhauer TA, Gessmann J. Revision of subtrochanteric femoral nonunions after intramedullary nailing with dynamic condylar screw. BMC Musculoskelet Disord. 2018;19(1):448. 
59. Nguyen TV, Pocock N, Eisman JA. Interpretation of bone mineraldensity measurement and its change. J Clin Densitom. 2000;3:107-19.

60. Sedrine WB, Chevallier T, Zegals B, et al. Development and ml-nent of the osteoporosis index of risk (OSIRS) to facilitate selection of women for bone densitometry. Gynec ol Endocrinol. 2002;16(3):245-50. https://doi.org/10.1 080/gye.16.3.245.250.

61. Boonen S, Koutri R, Dequeker J, Nijs J, Geusens P, Bouillon R. Geometric characteristics of the proximal femur in type 1 and type II osteoporosis. J Bone Miner Res. 1994;9(suppl 1):158.

62. Shu DP, Xiao YP, Bei MJ, Ji T, Peng YJ, Ma B, et al. Dynamic compression locking system versus multiple cannulated compression screw for the treatment of femoral neck fractures: a comparative study. BMC Musculoskelet Disord. 2020;21 (1):230. https://doi.org/10.1186/s12891-020-03259-5.

63. Güven M, Yavuz U, Kadioglu B, Akman B, Kilinçoglu V, Unay K, et al. Importance of screw position in intertrochanteric femoral fractures treated by dynamic hip screw. Orthop Traumatol Surg Res. 2010;96(1):21-7. https:// doi.org/10.1016/j.otsr.2009.10.008

64. Karrholm J, Garellick G, Rogmark C, et al. Swedish hip arthroplasty register. Annual report 2011. Sahlgrenska: Sahlgrenska University Hospital; 2012.

65. Huiskes $\mathrm{R}$, Weinans $\mathrm{H}$, van Rietbergen $\mathrm{B}$. The relationship between stress shielding and bone resorption around total hip stems and the effects of flexible materials. Clin Orthop Relat Res. 1992;274:124-34.

66. Guille JT, Kumar SJ, MacEwen GD. Fibrous dysplasia of the proximal part of the femur. Long-term results of curettage and bone-grafting and mechanical realignment. J Bone Joint Surg Am. 1998;80(5):648-58. https:// doi.org/10.2106/00004623-199805000-00005.

67. Wroblewski BM, Siney PD, Fleming PA, et al. The calcar femorale in cemented stem fixation in total hip arthroplasty. J Bone Joint Surg Br. 2000; 82:842-5.

68. Parker MJ. Cutting-out of the dynamic hip screw related to its position. J Bone Joint Surg Br. 1992;74(4):625.

69. Baumgaertner MR, Curtin SL, Lindskog DM, Keggi JM. The value of the tipapex distance in predicting failure of fixation of peritrochanteric fractures of the hip. J Bone Joint Surg Am. 1995;77(7):1058-64. https://doi.org/10.2106/ 00004623-199507000-00012.

70. Kuzyk PR, Zdero R, Shah S, Olsen M, Waddell JP, Schemitsch EH. Femoral head lag screw position for cephalomedullary nails: a biomechanical analysis. J Orthop Trauma. 2012;26(7):414-21. https://doi.org/10.1097/BOT. Ob013e318229acca.

71. Kashigar A, Vincent A, Gunton MJ, Backstein D, Safir O, Kuzyk PR. Predictors of failure for cephalomedullary nailing of proximal femoral fractures. Bone Joint J. 2014:96-B(8):1029-34. https://doi.org/10.1302/0301-620X.96B8.33644.

72. Huang C, Tan H, Kernkamp WA, Cheng R, Liang J, Zhu Z, et al. Effect of altered proximal femoral geometry on predicting femoral stem anteversion in patients with developmental dysplasia of the hip. J Orthop Surg Res. 2019:14(1):420. https://doi.org/10.1186/s13018-019-1491-4.

\section{Publisher's Note}

Springer Nature remains neutral with regard to jurisdictional claims in published maps and institutional affiliations.

Ready to submit your research? Choose BMC and benefit from:

- fast, convenient online submission

- thorough peer review by experienced researchers in your field

- rapid publication on acceptance

- support for research data, including large and complex data types

- gold Open Access which fosters wider collaboration and increased citations

- maximum visibility for your research: over $100 \mathrm{M}$ website views per year

At $\mathrm{BMC}$, research is always in progress.

Learn more biomedcentral.com/submissions 